\title{
Burnout: Drudgery, Repetition, Creativity
}

\author{
John Y. Wu ${ }^{1}$, Kuangming $\mathrm{Wu}^{2}$ \\ ${ }^{1}$ University of California, Davis, CA, USA \\ ${ }^{2}$ Philosophy Department, University of Wisconsin-Oshkosh, Oshkosh, WI, USA \\ Email:wutulare@yahoo.com, kmwu2002@yahoo.com
}

Received 7 April 2016; accepted 9 May 2016; published 12 May 2016

Copyright (C) 2016 by authors and Scientific Research Publishing Inc.

This work is licensed under the Creative Commons Attribution International License (CC BY). http://creativecommons.org/licenses/by/4.0/

\section{(c) (i) Open Access}

\begin{abstract}
Identical repetition composes drudgery that results in burnout. But besides identical, there can be repetition of daily routine, and also can be continuing creative novelty. We must dissolve burnout by turning identical repetition into regular routines of creative novelty. This essay is thus composed of three sections, drudgery, repetition, and creativity.
\end{abstract}

\section{Keywords}

\section{Low IQ People, Children, Geniuses, Difference, Turning}

\section{Introduction}

As our usual custom would have it, we often say that the devil would find for a lazy-bone an ailment to "busy" his days and while his life away. And so, we would theoretically expect health and wealth to bless and reward diligent people and to follow them all their days always, without exception. But strangely, contrary to our reasonable expectation, a special and widespread sickness tends to attend precisely those busy people, and precisely because of their busy struggles. It is burnout. How does it happen?

Diligence shows "reverence the human root", yet precisely this diligence can burn up these industrious people, in total exhaustion. It is incredible! We call it "burnout" that burns out these diligent people in their own heat of busy days, tiring them all out. The devil does also, without a fail, find an illness for diligent "busy bodies" as well as for lazy bones. It is never fun, never a good fortune, to suffer from burnout.

This essay is interested in burnout, for it is an important issue in life. Now being interested in burnout is odd, for burnout is burned out of interest, vainly suffering in helpless pain of boredom. But without interested consideration of burnout, burnout just stays hidden silently biting us, nowhere to find. And so, strangely self-contradictory as it may seem, interested concern for burnout is needed. After all, consideration of burnout can burn out the burnout itself.

In the end, we realize. Identical repetition composes drudgery that results in burnout. But besides being identical, 
there can be repetition of daily routine, and also can be continuing creative novelty. We must dissolve burnout by turning identical repetition into regular routines of creative novelty. This essay is thus composed of three sections, drudgery, repetition, and creativity, each increasing in its length because of increased complexity, as it goes to the next section.

\section{Drudgery}

Drudgery and repetition are of course some proximate causes of burnout. Its ultimate cause may or may not be our need to make money; medical burnout may not all be due to money-desire. But such ultimate cause is quite difficult to handle, e.g., on exactly how money causes burnout, and on how money influences how to dissolve burnout, besides dealing with drudgery and repetition as this essay does.

Burnout can interest us enough to initiate its consideration. Burnout can happen this way, through drudgery aware of identical repetition. Awareness of continuation of things identical comes from our memory that remembers one thing and then the thing next, and connects one thing to the next, to see that they are the same. Seeing such continuation then naturally breeds boredom, and then boring labor results in burnout. This happening is quite unpleasant but quite natural. Drudgery drones on, not arbitrary not creative, not for high IQ people not for kids; these people are casual arbitrary kids or careful creative geniuses, but none of them is never burned out.

Burnout results from recognition of drudgery, being aware of long drawn-out and ever repeated continuation of identical labor. And so, those low IQ people without memory have no burnout, as each happening to them is the very first in their life. They are forever happy, and burnout is quite foreign to them. We really envy them so very happy at each moment, as "Charlie" the moron in Flowers for Algernon so movingly describes, heartfelt (Keyes, 2005).

In contrast, sensitive people, constantly sharp and deep, often suffer from feeling that things continue repeating identically, due to their capacity of memory. As morons can go without burnout due to lack of memory, genius can do so by controlling their memory, and then for both geniuses and low IQ people, each event will happen for the first time since the creation of the world.

Burnout is thus for average people in the middle who are all of us, not moronic not genius. We are trapped in awareness of boring continuation of things and irksome drudge, and feel totally identical repeating. We common people can learn from people both moronic and genius who can rid us of feeling the continuing repetition of things identical, and burnout then disappears all by itself unawares.

Another group of people, medical doctors, face quite different challenges from challenges of assembly-line workers who keep screwing identical screws and soldering identical metal pieces. In contrast to assembly-line workers, after long decades of years of involved, complex, and concentrated training in restoring physiological damages, these medical doctors confront a whole host of patients who are in nagging persistent pain, suffering and fatigued, irritated, suspicious, and deeply worried. Faced with these people not at all pretty and friendly, the medical doctors cannot simply force on the patients their trained regimen, bullying patients into accepting their trained medical prescriptions.

Instead, medical doctors are forced first to assuage those battered patients, so worried and suspicious, with explanations in words understandable at patient's level—remember that their capability of understanding is already lowered extremely low by their suffering — of the patient's actual situation, and persuading patients by elucidating simply, accurately, and intelligibly, more pros to accept the proposed prescriptions than their cons to watch out for and be careful about.

Such careful detailed labors of the medical doctors are a sort of "counseling", their sensitive and careful "bedside manners" absolutely indispensable to medical therapy of whatever sort. Such counseling is amazingly unlimited in variety and in depths of differences. Naturally, medical doctors are so stretched out beyond their usual training range, and so they tend naturally to total exhaustion and burnout. These doctors require repeated vacations at regular intervals.

So, all these various workers suffer pain of burnout arising from two sorts of drudgery, straight recurrence and ingenuity routine. Fixed and expected goals are served by both drudgeries of routine repetitions. Tiresome repetition causes drudgery to cause burnout, however different these workers are.

\section{Repetition}

“Are all personal burnouts due to ‘drudgery’?” Well, they may be, but obviously some burnouts differ from 
some others due to different causes of burnouts. Medical doctors' "drudgery" is quite a different sort from "drudgery” among assembly-line workers. "Are all burnouts originated in 'repetitions'?” Again, all of them may be but there are repetitions and there are repetitions. Repetitions are not created alike at all.

Repetitions compose routines, trivial identical or serious numerous, mechanical or ingenious, requiring no training or long involved and complex training, no stimulation or too much stimulation. All of these repetitions, however different, drain our energy, induce our total fatigue, to collapse all of us in burnout of a same sort, for after all, we are all identically human, irrespective of intelligence difference or training difference, all subject to identical sorts of stresses and struggling pain.

Still, there are some differences. Operations in an emergency room combine counseling persuasion of patients with physiological repairs for which medical personnel are professionally trained for long. Medical performance is quite a difficult and laborious routine, as assembly-line drudgery is an easy routine. They are different. However different, however, both routines are repetitive and quite tiresome, and often lead us to helpless pain of burnout.

Moreover, importantly, continuous stimulation in an emergency room is not continuation of really stimulating novelty; new patients continuing to come would tire out medical personnel, because such stimulation is not creative but restorative in a standard expected manner, not "novel" in a truly creative sense. Medical therapeutic operations are quite tiresome, though they differ from drudgery in an assembly line performance.

Of course, when tired out and burnout, we all instinctively stop what we are doing, and take a day or even several days off, and then we recuperate into our old vibrant self, ready to plunge into our familiar chores and responsible duties. Interestingly, however, many things and events continue repeating identically and we feel no burnout. For instance, we continue to breathe identically from one moment to the next as we routinely live on identically.

We sleep regularly each day at 24 hour intervals and we enjoy our identical sleep. We eat regular meals and snacks from one day to another, often identically, and we always enjoy them with gusto without exception. We do not mind each calendar day going identically from one day to another, at least as we flip calendar sheets. For regular repetitions of common days, rarely do we go see the doctor. And the list goes on continually, so much so that "burnout" is an exception in life that continues repeating identically on and on. Does this fact comfort us out of our burnout, as we realize now that "being identical" that does not exist in life is not "being steady" that means to be alive on and on?

Let us return to two sorts of drudgeries, two sorts of routines, to result in two kinds of outcomes, namely, assembly-line drudgery and medical-hospital drudgery, yet both end up in the same human burnout. The assembly-line drudgery consists in simple repetition of identical operation. The medical-hospital drudgery is an expected custom-making physiological healing endeavors, to which appends an expected persuasion of the patients to coax the patients' consent to the prescribed regimens customized to fit their special situations unique to each patient.

Since human persons are amazingly various, we naturally expect that an amazing variety of ingenuity is required to accomplish the expected double goals of custom-making medical regimens and variously persuading various patients to these regimens. So medical hospitals are filled with amazing amounts of complexities, and besides, such situations happen on a daily basis. The hospital is a bewildering "jungle" of innumerable outpourings of ingenuities.

Still, such complex situations in the hospital are naturally expected, and continually drone on regularly, to tire out medical personnel. Such is the medical routine usually expected in the hospital. This hospital routine naturally expected naturally drains out the medical energies of hospital workers. Whatever ingenuity required is under the expected rubric of medical double goals of customizing healing and persuading patients. Medical ingenuity is thus far different from genius creative novelty that is often totally unexpected and so exciting.

We have been considering burnout. Burnout is due to prolonged drudgery of both sorts, both identical and expected, in an assembly-line and in the hospital, in repetitions identical and ingenious. Burnout is thus caused by repetition; repetition is the culprit that burns us out, exhausted. In this manner, repetition is quite bad and blamable. But "repetition" is much wider and more various in kinds than the one causing drudgery.

Repetition ranges at least over three horizons, namely, to cause drudgery, to pervade in daily living, and to create novelty. Besides causing drudgery, the first area other than drudgery is daily ongoing. Our heart pumps repeatedly, as we breathe continually, as we enjoy eating at regular intervals, and as we sleep and wake up, day in and night out. Our daily living consists in continuous repetitions of various sorts to prolong living. Furthermore, thirdly, we imagine unimaginable thoughts, and act out occasionally to surprise even ourselves. We call 
such repetition "creative novelty".

To repeat this important point, we see that repetition is of three kinds: one, to cause burnout, two, to live on, and three, to create. Low IQ people live in repetitive living and enjoy the stark repetition of their living. This is because they do not have the capacity to remember the past events enough to connect the past to the present happenings, so as to recognize repetition of things identical, and so, to these low IQ folks there exists no repetition. Every event happens for the first time in the world. Without boring repetition, these people are forever happy, and so, they could never have burnout.

Our second groups of people are the people we call "children". Children are naughty and contrary, to constantly raise the eyebrows of Mom and Granny who love them dearly. Children thus constantly stretch forward toward creative novelty to often offend regular routines. Children are forever curious and always excited at the here now status quo that forever catches their wonder, as low IQ people are ever starkly present and are happy in their own peculiar manner.

When children are confronted with repetitions, they are of course bored, complaining "nothing to do!” But they are not burned out due to their undying curiosity; as their curiosity never dies, they never get burned out of their curiosity. In addition, wonder of wonders, these children do also amaze us by insisting, "Do it again!” We would have thought that curiosity always hunts things that never repeat, and so repetition has nothing to do with children.

But things familiar to children do appear quite often to them, and they do surprisingly insist on repeating things familiar to them. We understand how repetition can turn children bored as the low IQ folks are never bored. But how children's curiosity is related to their request to repeat what are familiar to them is quite a mystery to our common sense. The low IQ people have no capacity to remember past events and so they have no repetition, but children do remember things and do recognize repetition.

Still, to think of it, we average people, while getting bored at identical things identically repeated, do love to listen to old familiar musical compositions, and do love to visit quite often our old favorite park and even our familiar restaurant. We are actually kids of all ages, and want to "Do it again!" after all. Does familiarity make our home? Do things familiar to us, when incorporated into our living days repeatedly, turn into parts of our favorite routines to assure us of our daily ongoing so safe, cozy, and dependable, on and on?

Now, our third groups of people are geniuses who are sensitive to things around them, and so of course they notice that things commonly happening do often repeatedly happen. Geniuses can even get burned out, then, but soon enough they would bounced back to discover repetition as a common fact of life, and they are smart enough to turn such common fact of repetition into a steady outpouring of creative novelty.

We middle-class people are regular, alive, and regularly waver between repetition of drudgery, repetition of living, and repetition of novelty. Our ever uncertain wanderings make us envy low IQ people who always enjoy themselves in steady routine of ordinary living, as well as admiring children who are naughty enough to offend usual decent people. We are neither naughty as children, nor are we steady enough as low IQ folks to afford to enjoy ordinary daily living. We end up sinking into burnout in much pain. Poor we, so sad!

Now, the point of all this description is clear. We must turn around to become aware of what is going on in us and around us. We must be conscious that, when repetition of drudgery comes on us to press us down into exhaustion quite helpless, we must at once lift our head above it to mind the low IQ people who continually enjoy routine regularity that includes what we take as drudgery, for drudgery does not exist for these low IQ folks enjoying repetitive routines on and on.

Moreover, we must jump with those impossibly naughty children all beyond Mom's handling. We must then engage in unimaginable cranks beyond repairs, beyond expectation, and quite unpredictable. Naughty insights are always contrary to what exists usually. These insights come with lightning, and then just as suddenly they disappear, and then suddenly come again, to suddenly go again. These insights are always jumping alive, repeating themselves, never staying put.

We let ourselves go, as we are inspired as children jumping around all over, devil may care! And when we are burned out, we let go of it. All such continuous "letting, and letting go of" are personal repetition, this time so thrilling. Such is repetition of creative novelty in which drudgery disappears to cease to burn us away. Now we are far off, far distant from burnout. Such creative novelty is the key, to which we now turn.

\section{Creativity}

The many senses of repetition described above give birth to our decisive salvation from burnout, into outright 
metamorphosis of the daily world, in creative novelty in our diligence. Such is the sheer smile of this final section. Now we go into the excitement of creative novelty, so amazingly complex, as its complexity composes our excitement.

Steady stimulation of creative novelty from one day to the next cures fatigued boredom, and then burnout is nowhere to be found. Routine happenings of novelty so surprising each time, now compose daily ongoing, steady and jumping alive. It is in sync with routine happenings, to repeat novel things without repeating them. To realize all this is inevitable for geniuses sensitive to identical repetition. Even we ordinary people can learn from geniuses to recognize that routine happenings of daily novelty is quite exciting, never boring.

In fact, such is a typical ongoing of kids - are they geniuses, then? - whose living days are a continuation of fascinations one after another. And so kids are always jumping alive, full of curiosity, even at "common" pebbles that are their pearls so precious, deserving of bartering among them. Their barters are themselves a sight to behold! Whatever they do, even casually falling asleep in Mom's loving embrace, is fascination continuous, and continuous fascination is quite distant from exhaustion leading us to burnout all painful all helpless.

Here the sublimity of beauty in serene truth is closely followed by eternal goodness that forever attracts us. And then, all things appear to us cohering into individual self-identity, and each being sparkles in individual awesome dignity, never to intrude and ever to admire. Boredom is killed as meet each dignified self-identity of each thing, as burnout vanishes into thin air with fragrance existential. Fragrance pervades, so ephemeral throughout all things so solid, steady, and incorruptible.

Still, we do sometimes suffer from burnout. Devotion to the Beyond could help, to enable us to switch from burnout to creative work available to sensitive geniuses who are ever susceptible to burnout even in daily routine. Daily routine is steady, not identical, and geniuses can take advantage of steady routine to do creative work of novelty continuous. Steady continuation of novelty is not repetition of things identical.

Now, I am one of the common people smack in the middle of all people. As a middle common person, I vainly admire children and low IQ people, ever without boredom, much less burnout. I am not child enough with curiosity to an undying extent, and so I cannot enjoy as a child the repetitions of things each of which turns up different to satisfy my curiosity. In addition, I was born with more IQ than low IQ people, and so, I am incapable, as they are, of welcoming with excitement each event as the very first in the world. My life can never be as fresh as those dear beloved low IQ folks.

Of course, I try my very best to be "naughty as a child". Ten years younger than my senior model brother Christian, I act as a "bad boy" of eternal rebel heretic, forever mumbling, "Yes, but" to things traditional and correct, ever. Nothing may be new under your sun, but it is in this way that everything is brand new so exciting under my sun. This is how my exultant excitements keep happening; all such is my excitement to find excitements everywhere I look, on and on, world without end.

For instance, I am excited at our common space in common time constantly embracing each other. First, space is timed. I often forget myself engulfed in playing with children, turning every moment into eternal space. But then, in the meantime, being with children, however "eternal", soon passes and is over, as those children soon enough grow up and would not take a second look at me, such an old decrepit fellow, though he, me, still loves them dearly. And then, secondly, time is spaced. I constantly dwell myself in playing with children yesterday, and that yesterday lasts spatially, forever, in my soul, in spaced time never corrupt.

Space and time interpenetrate this way to compose to present irresistible life situations, one after another. Such space-time interpenetration is often missed in our usual thinking that thinks either space alone or time alone, and then our thinking gets lost in tons of mist, ambiguous somewhere. But space-time interpenetration is everywhere so common. Music, say, is the spaced time dynamics. Painting is timed space alive. Poetry can be either and both. In the beginning is the word, indeed. Words sing, and words paint. This present description here is executed in words. The whole world beams with undying beauty of music, of painting, and of words.

Now, understanding painting or music or poetry, anything beautiful, is to undergo heartfelt appreciation of what is expressed heartfelt. "Does beauty have a heart?” How plebeian you are, my friend! Beauty without heart is no beauty, don't you know? The point here is that beauty has no "objectivity". Beauty is forever inter-subjective, deep answering deep. Beauty is the art of music, of painting, of poetry, all scintillating, all irresistible to charm us into the whole world singing so irresistibly.

The world is an artwork where the artists and the admirers meet heart to heart, soul in soul, intensely cherishing one with the other. Arts are beauty heartfelt in sensitive perception, concrete and deep, all too concrete too deep for words, except for poetry of deep sighs in music in painting, and in the hearts of the artists and of the 
admirers. And mind you. Artists and admirers are everywhere in the world, to sing to paint the world, together, forever irresistible.

And mind you again on this further point. Such appreciative enjoyments of art-creation and art-appreciation never come in a slab of complete and explicit system. They always come in bits and pieces, each eternally spaced and eternally timed, interpenetrated interpenetrating. And as such, each seemingly separate bit mirrors and shimmers in a tacit and complete "system" ineffable.

This tacit and complete system is the entire world looked at from one perspective, and sung in one specific tune-beauty. Each bit is a complete system, however tacit, that as such composes a systematic chapter of the world ever in the making, totally concrete, as the world as a whole system is absolutely concrete ever invisible. All such is my childish vision, both specific and concrete, and as such all-comprehensive.

Still, it remains that I this tiny self am a "clumsy child" never as nimble as any of these children shouting and jumping, and of course I can never emulate the low IQ people. Since I am unable to learn from irresistible children, much less from the dear low IQ people, I will try to follow, even quite clumsily and distantly, those admired geniuses who take repetitions in stride, and take advantage of these repetitions of things and events as steady and constant, and spontaneously create no less than sheer immortal poetry of living, forever quietly sparkling, never burned out because the novel creation is ever under construction, never complete enough to bore us.

Incredibly, interestingly, it is thus that burnout can incite repetition of daily novelty; it is a routine creativity that can often tend toward "soothing burnout", however contradictory this phrase may sound. The crucial key here is to raise our mind beyond helpless quicksand of helpless burnout, and take advantage of routine repetition that is Janus-faced, and turn its burnout-face to novel creativity-face, again and again.

Such a turning turns pain of repeated burnout into joy of repeated creativity. Moreover, we must remember this significant point in this context. Importantly, burnout as any other psychic ailment does not get "healed" in full awareness. Burnout just vanishes unawares in thin air while we are engaged in repeated excitements of emerging creative novelty, all quite irrelevant to our pain of burnout.

"Where is science?” Well, can you not see? Science is proud of forever in progress, and "progress" connotes forever incomplete, forever under construction, and, surprisingly, such construction often tears down what was previously completely constructed. Scientific progress is actually continuous revolution in novelty into further novelty, and "novelty" can never be predicted in advance. Advance in science is a typical case of creative novelty totally dynamic, forever forwarding and unpredictable. No shadow of burnout can be detected anywhere anytime, in science ever in progress.

"But then, how can we turn boring tiresome repetition into novel creative repetition?" Now, this is an important question. We can see at least four ways, sleep, music, religion, and writing, among others so indefinitely many that are commonly laying around us, constantly. These four ways already show how common and ubiquitous those ways of turning are, all depending on our opening sensitive eyes to them.

One, sleep: When tired out, we instinctively crawl into bed and fall asleep. Sleep sinks the subject into the subject. Since all our consciousness is directed away from our self toward objects outside us, subject gone into subject sinks away our awareness, quite unawares. Such is our self coming home to our self, and self-homecoming nourishes our whole self as nothing else whatever can do (Wu, 2014).

We turn fresh, alive, after sleep, whether in a short nap or in a long dreamless sleep at night every 24 hours. In fact, our whole vigor to be our self depends totally on such sleep, short or long; depriving us of sleep deprives us of life. Burnout is thus slept away and swept far away unawares in sleep unawares. Strange as it may seem, unawareness is an oceanic feeling in which we swim, as in the ocean called "my self". Nothing can intrude here; everything is at home here, profoundly self-nourishing, to nourish us away from burnout.

Two, music: Have we noticed how always children are humming the tunes they made for themselves as they play all day? That life-as-music is children's life lyrical and vigorous. We the children of all ages lead our life precisely and spontaneously as we live in rhythm of music, whether listening to our favorite compositions or humming our favorite tune, however truncated.

Such drenching is music that dips us into our rhythm of living, and such total living in natural rhythm of music of life nourishes us unawares into our primal tunes of life, exactly as sleep that enables us unawares to come back home to our total self, all unawares. Music is actually our nourishing sleep all-awake, our sleep-homecoming in daytime, to invigorate us into our primal self. Music is our primal self-power. In such invigoration into our primal self, burnout cools itself away in musical rhythm that is our primal rhythm of life.

Three, religion: If both sleep and music are our homecoming to ourselves so sweet so nourishing, we must 
remember that both sleep and music are actually the forerunners in this world to our ultimate homecoming to the Beyond-all in the world out of the world, as this ultimate homecoming is called "religion". Every single day and single night are progressing forward somewhere, and that "somewhere" that keeps going on forward ultimately goes into the ultimate Beyond-all that is our ultimate home. Our ultimate home is our final bird-nest, our absolute fox-hole, where we pillow our head in the safety of our soul comfort.

Religion is our final Home, where things are a vapor to blow around here and there, as Buddha says, or else religion is our destined Home where all trumpets forever blow Halleluiah in new Heaven and new Earth; here all tears of sorrow turn into tears of joy, on and on, world without end, as Christianity tells us. In the end, we realize how our vaporous life here today prepares us day by day for that ultimate Home still on its way.

Buddha is smiling with Jesus to beckon us over there. Religion is thus our final and ultimate comfort, for which we live, after all. Without such final joy-destination, our days are leaves in the autumn blowing about helplessly for the chill of snowy winter. Religion is our final Home ultimately to burn away all burnouts that tend to cling on to us exhausted, in the meantime while we are heading there.

Four, writing: Any casual putting down of any ideas on paper is surprisingly everlasting. Ancient Chinese Chuang Tzu's quip 22/39, "Our life is brief as a white colt passing through the door crack", said 2500 years ago, is still here today to make us sigh. Actually, I do not know what ideas I have until my fingers write them down on paper for me. Writing finds my ideas, and firms them up forever as mine forever.

Words seem so hollow and unreliable, yet once "stood" and set up in writing, they last "incorruptible" immortal, says China that keeps writing for many millennia; China is an eternal kingdom historic and literary. Any writing firms me up, confirming me as my self, on and on, everlastingly to please me in front of me. Writing is my eternal pleasure in which all burnouts vanish unawares.

Now, there must be many more ways to turn boring repetition that sires burnout into exciting repetition that invigorates life on and on. All repetitions constantly go on and on, and it is up to us to turn it into what jumps us up alive with children jumping alive. The key is in our hand and in our heart of hearts. We must wake us up into sleep, hum along any favorite tune-bits that comes on to us, press spontaneously toward the final Home called religion, and keep writing on paper whatever comes to mind, and enjoy whatever arises in our humble writing day by day. Burnout would have no room even to sneak itself in. The turning is the key to joy forever, for which we all live.

\section{References}

Keyes, D. (2005). Flowers for Algernon. New York: Mariner Books.

Wu, K. M. (2014). The Gospel of Self-ing: A Phenomenology of Sleep. Open Journal of Philosophy, 4, 117-129. http://dx.doi.org/10.4236/ojpp.2014.42016 